\title{
Establishment and characterization of a human papillary thyroid carcinoma cell line with oxyphilic differentiation (ONCO-DG 1)*
}

\author{
Daniela Grimm ${ }^{1}$, Ferdinand Hofstädter ${ }^{1}$, Johann Bauer ${ }^{1}$, Thilo SpruB ${ }^{2}$, Pia Steinbach ${ }^{1}$, \\ Günther Bernhardt ${ }^{2}$, and Rita Menze ${ }^{1}$ \\ ${ }^{1}$ Department of Pathology, University of Regensburg, Franz-Josef-Strauß-Allee, W-8400 Regensburg \\ ${ }^{2}$ Department of Pharmaceutical Chemistry, University of Regensburg, Federal Republic of Germany
}

Received July 18, 1991 / Accepted March 30, 1992

Summary. In the present study the establishment and characterization of a new oxyphilic papillary thyroid carcinoma cell line - ONCO-DG1 - is given. With immunohistological, histochemical and flow cytometric methods, ONCO-DG 1 cells revealed features of epithelial differentiation. Furthermore the cells formed von Kossa-positive deposits resembling psammoma bodies in monolayer and spheroid culture until late passages. The tumor cell line is now in the 40th subculture. Because of the ability to form multicellular tumor spheroids (MCTS), this cell line is a good model for examining the interaction between thyroid tumor cells and confluent human endothelial cells on extracellular matrix in vitro. It is also suitable for xenotransplantation studies, because it is tumorigenic in NMRI nude mice in vivo.

Key words: Papillary thyroid carcinoma - Psammoma bodies - Multicellular tumor spheroids

\section{Introduction}

The establishment of a suitable thyroid carcinoma cell line provides a in vitro system allowing a clearer understanding of the function of malignant thyroid tissue. So far rat thyroid tumor cell lines e.g. FRTL-5 (Mulcahy et al. 1985), the continuous cell line MTC-SK (Pfragner et al. 1990) and other cell lines derived from human medullary thyroid carcinomas as well as the follicular thyroid cell line UCLA RO 82 W1 (Estour et al. 1989) are established. However, a papillary thyroid carcinoma cell line with oxyphilic cell differentiation has not been available previously.

By WHO definition, papillary thyroid carcinomas are malignant epithelial tumors showing evidence of follicu-

* Supported by the Deutsche Forschungsgemeinschaft, (DFG, Gr 1039/1-1), Bonn, FRG

Offprint requests to: D. Grimm lar cell differentiation with papillary and follicular structures as well as characteristic nuclear changes (Hedinger et al. 1988). They spread preferentially to lymph nodes but may also metastasize to distant organs, particularly the lung (Hedinger et al. 1988). We are interested in studying differentiation criterias and the metastatic behavior of thyroid tumors in vitro and in xenotransplantation experiments. For this purpose it is necessary that the cultured cancer cells are tumorigenic in nude mice. Furthermore it is important that the cells have the ability to form multicellular tumor spheroids (MCTS), which represent small avascular tumors (Knüchel et al. 1988). The cell line ONCO-DG 1 meets these requirements and may in future be a useful model for coculturing MCTS with confluent human endothelial cell monolayers, in order to study cell-cell-interactions in lymphatic and hematogenous tumor spread.

\section{Materials and methods}

Tissue culture media. The medium used was RPMI 1640 (Biochrom, Berlin, FRG), supplemented with fetal calf serum (FCS 10\%) (Gibco, Eggenstein, FRG), sodium pyruvate $100 \mathrm{mM}$ (Sigma Chemie, Deisenhofen, FRG), L-glutamine $2 \mathrm{mM}$ (Sigma Chemie, Deisenhofen, FRG), 100 units penicillin $/ \mathrm{ml}$ and $100 \mu \mathrm{g}$ streptomycin $/ \mathrm{ml}$ (Biochrom, Berlin, FRG).

Isolation and establishment of the cell line. Malignant tumor tissue was obtained from a 49-year-old female patient with a well-differentiated oxyphilic papillary thyroid carcinoma (PT2, G1, No, Mo). A sample of this tissue measuring $1 \mathrm{~cm}^{3}$ was mechanically dissociated and then treated with $2 \mathrm{ml}$ of a mixture of $0.1 \%$ collagenase and dispase (Boehringer, Mannheim, FRG) for $30 \mathrm{~min} 37^{\circ} \mathrm{C}$ in $5 \% \mathrm{CO}_{2}$ to obtain a single cell suspension. After incubation the enzymatic action was stopped with RPMI 1640 medium containing $10 \%$ FCS. Cells were spun down in a tube (Greiner, Frickenhausen, FRG) for $10 \mathrm{~min}$ at $2000 \mathrm{rpm}$. The supernatant was discarded and the pellet was resuspended in tissue culture medium. Some of the cells were plated in culture flasks (Greiner, Frickenhausen, FRG) and the rest were stored in liquid nitrogen for future use $\left(P_{0}\right)$. The cells were grown as monolayer cultures and as MCTS, the incubation being conducted at $37^{\circ} \mathrm{C}$ in a humidified atmosphere of $5 \% \mathrm{CO}_{2}$. The medium was changed at intervals of 3 days. 
Table 1. Panel of antibodies used for immunohistochemistry

\begin{tabular}{lllll}
\hline Antigen & Clone & Isotype & Dilution & Company \\
\hline Cytokeratin & KL 1 & m IgG1 & $1: 100$ & Immunotech \\
Thyroglobulin & DAK-TgG & m IgG2 & $1: 150$ & Dakopatts \\
Vimentin & Vim 3B4 & m IgG2 & $1: 10$ & Progen \\
Actin & asm-1 & m IgG2 & $1: 50$ & Boehringer \\
Desmin & 023 & r IgG & $1: 50$ & Euro-Diagn. \\
CEA & Lot 067 & r IgG & $1: 100$ & Dakopatts \\
\hline
\end{tabular}

Immunotech, Dianova, Hamburg, FRG

Dakopatts, Hamburg, FRG

Progen, Heidelberg, FRG

Boehringer, Mannheim, FRG

Euro-/Laboserv Diagnostics, Gießen, FRG
Cell viability was tested with the trypan blue method. Mycoplasma testing of cultures and controls was negative.

Culture of MCTS. Tumor cells from adherent growing cultures of ONCO-DG1 and from dissociated nude mouse tumors were used to form multicellular tumor spheroids. The tumor cells were harvested using a mixture of trypsin and EDTA 0,25\% (Biochrom, Berlin, and Sigma Chemie, Deisenhofen, FRG); viable cells were counted in a hematocytometer (Neubauer) after dilution in trypan blue. Samples of 4000 cells $/ 200 \mu \mathrm{l}$ (Coulter counter from Coulter Electronics, Krefeld, FRG) were seeded out in each well of a 96microwell test plate (Nunc GmbH, Wiesbaden, FRG) coated with $1 \%$ agarose (Sigma Chemie, Deisenhofen, FRG), and the medium was changed every second day.

Tumorigenicity: $A$ - animals and housing conditions. NMRI nude mice for the in vivo tumor experiments were bred in our animal laboratory. Animals were fed ad libitum with a combined breeding/ maintenance diet (1434, Altromin, FRG) and water containing $1.3 \mathrm{~g} / 1$ potassium sorbate $(5118$, Merck, Darmstadt, FRG) and $2 \mathrm{~g} /$ 1 chloramphenicole (C 0378, Sigma, Deisenhofen, FRG); the $\mathrm{pH}$ was adjusted to 2.5 with HCL. The animals were housed in macrolon cages (size II, Ehret, FRG) under pathogen-free conditions at $25^{\circ} \mathrm{C}, 70 \%$ relative humidity, and a $12 \mathrm{~h} / 12 \mathrm{~h}$ light program.

$B$-Tumor implantation. Initially, $10^{7}$ tumor cells in $0.1 \mathrm{ml}$ phosphate-buffered saline (PBS) from monolayer cultures were inoculated subcutaneously into the right flank of 8-week-old male NMRI $(\mathrm{nu} / \mathrm{nu})$ mice, following which solid tumors developed within 2 months. For serial transplantation the solid tumors were cut into $2 \mathrm{~mm}^{3}$ pieces and implanted with a trocar (ga. 13) into the right flank of 8-week-old male mice. The tumor area was determined as the produced of two perpendicular tumor diameters.

Part of each solid tumor was frozen in liquid nitrogen for immunohistochemical examination and some was used to establish the cells again in monolayer culture.

Microscopy. Cells grown in plastic culture flasks (Greiner, Frickenhausen, FRG) were examined by phase contrast microscopy (Leitz, Wetzlar FRG). Histochemically as well as immunohistochemically stained cells were observed by light microscopy (Leitz). After labeling with fluorescent dyes (FITC, rhodamine) single cells and MCTS were investigated either by fluorescent microscopy or by confocal laser scanning microscopy (Leitz, Wetzlar, FRG).

Histological staining. For histological analysis the primary tumor, the xenograft tumors, the monolayer cells and multicellular tumor spheroids were stained with hematoxylin and eosin. The presence of psammoma bodies was demonstrated by silver staining according the method of von Kossa.

Immunohistochemical staining. A: For immunohistochemical staining of monolayers, 2000 cells were seeded out into one chamber (8-chamber, Flexiperm, Renner, Darmstadt, FRG) and grown for 4 days. Subsequently the monolayers were washed twice in PBS, fixed with methanol and ethanol $(1: 1)$ or acetone and treated with the antibodies listed in Table 1. Antigen-antibody complexes were visualized with the indirect peroxidase technique (Polak et al. 1986). The incubation with the first antibody was followed by incubation with the second antibody. After repeated washing with PBS and exposure to diaminobenzidine (Sigma Chemie, Deisenhofen, FRG), the specimens were dehydrated and embedded with entellan (Merck, Darmstadt, FRG) and covered with glass slides.

B: For immunohistochemical staining of MCTS (7 days old), they were washed twice in PBS, fixed with methanol and ethanol $(1: 1)$ or acetone, processed through ascending grades of alcohol, embedded in paraffin wax, sectioned at $5 \mu \mathrm{m}$ and stained with the indirect peroxidase method.

Staining with rhodamine 123 (Goldstein 1981). The purified laser dye rhodamine 123 (R-302, Molecular probes, INC. Eugene, Ore, USA) was made up as a stock solution in dimethyl sulfoxide at $1 \mathrm{mg} / \mathrm{ml}$ and kept at $4^{\circ} \mathrm{C}$ in the dark. Rhodamine 123 was diluted in RPMI 1640 medium to $10 \mu \mathrm{g} / \mathrm{ml}$ and added to the cells which had been seeded out into a lab tec chamber slide (Nunc GmbH, Wiesbaden, FRG) 1 day previously. They were incubated for $30 \mathrm{~min}$ at $37^{\circ} \mathrm{C}$ in $5 \% \mathrm{CO}_{2}$.

After incubation the cells were washed twice with PBS and then used for live-cell observation with a confocal laser scanning microscope (Leica, Wetzlar, FRG).

Flow cytometry: A-staining for cellular antigens. A panel of commercially available antibodies was used for detecting cellular antigens. Mouse monoclonal antibodies against cytokeratin (conjugated with FITC), vimentin and thyroglobulin (both unconjugated), as well as a rabbit anti-CEA antiserum were obtained from Dako (Denmark). In each test antibodies or antiserum was added to $10^{5}$ cells fixed in ethanol $(70 \%)$ using the antibodies at saturation concentrations. The cells were incubated for $60 \mathrm{~min}$ at room temperature in the dark and washed three times with PBS containing $2 \% \mathrm{FCS}$. The cells treated with unconjugated antibodies were then incubated again for $45 \mathrm{~min}$ at room temperature with FITC-conjugated anti-mouse IgG or swine anti-rabbit IgG antisera and washed afterwards. Prior to flow cytometric measurement the cells were again incubated at $37^{\circ} \mathrm{C}$ for $60 \mathrm{~min}$ in the presence of $50 \mu \mathrm{g}$ RNase and $10 \mu \mathrm{g}$ propidium iodide in order to obtain additional information about the DNA content.

$B$-Preparation of cell suspensions using the modified method of Volm (1985). Non-necrotic tumor samples were freed from fat, muscle and soft tissue. The specimens were covered with Hanks' balanced salt solution (HBSS) and then cut into small pieces with a scalpel, scraped and suspended in HBSS. The resultant cell suspension was cannulated several times, pipetted with a sharp-edged glass pipette and then collected in Eppendorf tubes (Eppendorf, Hamburg, FRG), spun down in a Beckman centrifuge (Beckman Instruments, 

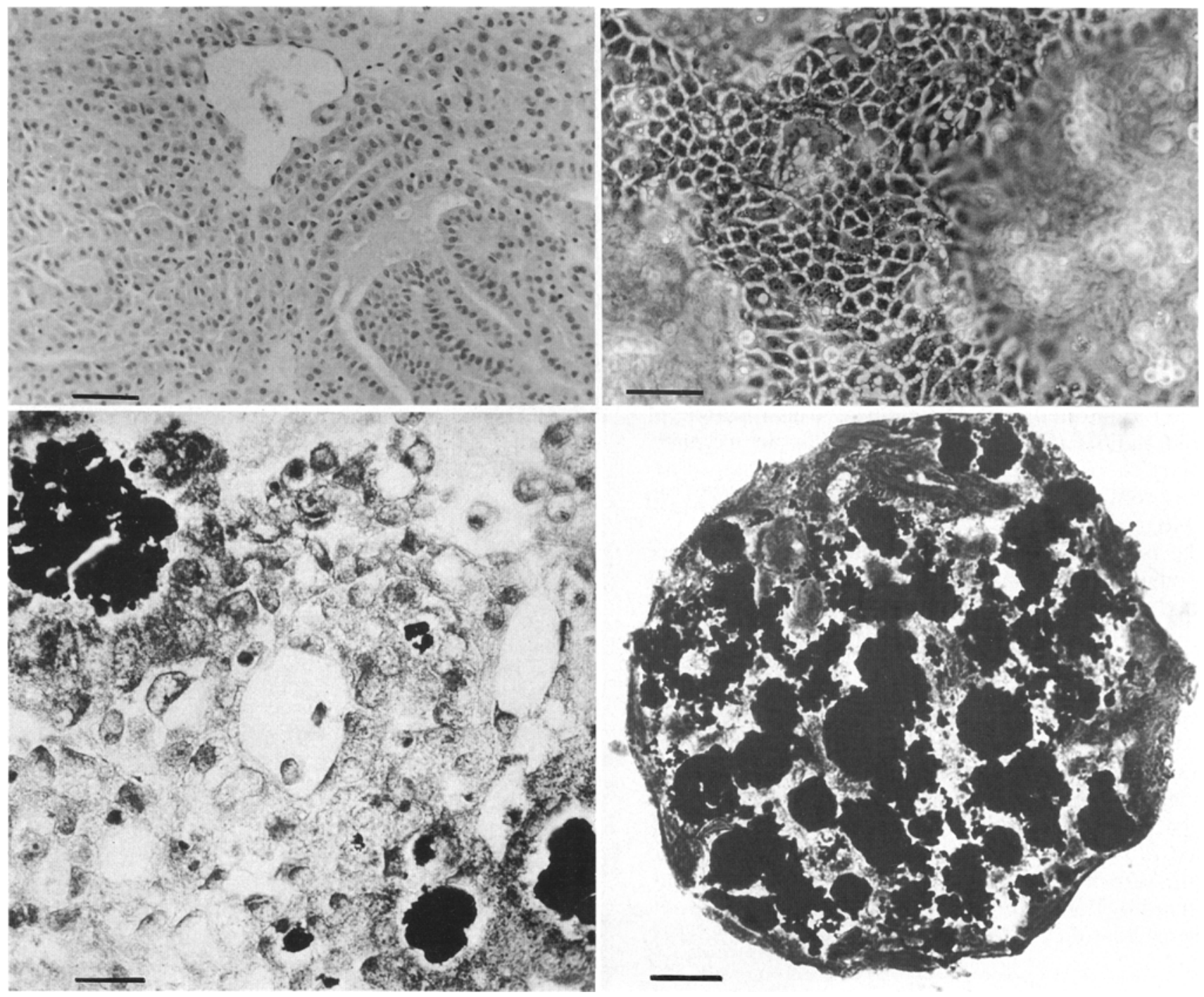

Fig. 1. Paraffin section of the primary tumor, an oxyphilic papillary thyroid carcinoma. The thyroid epithelial cells have finely granulated cytoplasm. Vascular invasion is evident. Hematoxylin-eosin staining (bar $=23 \mu \mathrm{m})$

Fig. 2. Morphology of cultured papillary thyroid carcinoma cells (ONCO-DG 1) grown two-dimensionally in culture flasks showing

the cuboidal epithelial cells growing confluently. Phase contrast $($ bar $=18 \mu \mathrm{m})$

Fig. 3A. Monolayer with laminated psammoma bodies, von Kossa staining $(\mathrm{bar}=7 \mu \mathrm{m})$ B MCTS (7 days old) passage 6. Paraffin section, von Kossa silver staining $($ bar $=50 \mu \mathrm{m})$

Munich, FRG) for $10 \mathrm{~min}$ at $2500 \mathrm{rpm}$, fixed with an ethanol:PBS (7:3) solution and stored at $4^{\circ} \mathrm{C}$ for $24 \mathrm{~h}$. Following this, the cell suspension was filtered through gauze (pore size, $200 \mu \mathrm{m}$ ), and the cell count was adjusted to $10^{5}$ cells $/ \mathrm{ml}$. This cell suspension was used for flow cytometry.

C-Flow cytometry analysis. Cell suspensions were measured in a FACScan flow cytometer (Becton Dickinson, Heidelberg, FRG) equipped with an argon laser emitting at $488 \mathrm{~nm}$, used to excite the immunofluorescence dyes and to measure the cellular light scattering properties. FITC fluorescence was measured using a 530/ $30 \mathrm{~nm}$ bandpass filter, and propidium iodide (PI) fluorescence was measured using a $600 \mathrm{~nm}$ longpass filter. The instrument was standardized each day for mean channel fluorescence with fluorescent microspheres (CaliBRITE-Beads, Becton Dickinson, Heidelberg, FRG). A minimum of 15000 events were counted for each sample, and the results were stored in list mode. The final processing of the results was performed using the Lysis Il-DATA Management system (provided by Becton Dickinson). Cells displaying fluores-

cence intensities above the upper limit of the negative control distribution were considered positive. Cell debris was gated out based on PI fluorescence thresholds.

Chromosome analysis. For this purpose the cells were grown to about $50 \%$ confluence on microscopic slides. In order to inhibit spindle formation, the slide chambers were inoculated with colchicine solution (Serva, Heidelberg, FRG) to a final concentration of $0.04 \mu \mathrm{g} / \mathrm{ml}$ and incubated for $3 \mathrm{~h}$ at $37^{\circ} \mathrm{C}$. The medium was replaced with $0.075 \mathrm{M} \mathrm{KCl}$. After $30 \mathrm{~min}$ incubation at $37^{\circ} \mathrm{C}$ an equal volume of cold, freshly made fixative (absolute methanol) glacial acetic acid 3:1) was added. This hypotonic/fixative mixture was removed immediately and replaced twice with ice-cold, fresh fixative. The slides were than air-dried and the chromosomes were stained for $8 \mathrm{~min}$ with $10 \mathrm{ml}$ Giemsa plus $90 \mathrm{ml}$ of $0.025 \mathrm{M}$ $\mathrm{KH} 2 \mathrm{PO} 4, \mathrm{pH} 6.8$.

The chromosome number of 50 well spread metaphases was determined using an Olympus BH-2 microscope with a $60 \times$ SPlanApo (oil) objective (Olympus Optical Co. Ltd., Tokyo, Japan). 
The microscopic image was focused through a NFK $2.5 \times$ photoeyepiece to a Panasonic F $10 \mathrm{CCD}$ videocamera (Matsushita Communication Industrial Co., LTD., Osaka, Japan). For image analysis the video signal was transformed in a PIP-512/1024 A video digitizer board (Matrox Electronic Systems LTD., Quebec, Canada) installed in an Olivetti M24 personal computer (Ivrea, Italy) and visualized on a SONY PVM-1371 QM video monitor (Tokyo, Japan). The chromosomes were marked with a mouse and counted automatically using an image processing program.

\section{Results}

\section{Primary tumor}

The primary tumor (Fig. 1) was classified according to the WHO International Histological Classification of thyroid tumors (Hedinger et al. 1988) as an oxyphilic papillary thyroid carcinoma. The tumor was staged according to TNM (UICC 1989) and graded as pT2, No and Mo.

The tumor was well-encapsulated, showing evidence of papillary formations and follicular structures as well as solid areas. The tumor consisted of oxyphilic cells with large nuclei, prominent nucleoli and fine-granulated oxyphilic cytoplasm. Capsular and vascular invasion was found.

Immunohistochemical staining of the primary tumor with the panel of antibodies listed in Table 1 against several antigens showed positive staining for cytokeratin, vimentin, and weak positively for carcinoembryonic antigen. Weak staining for thyroglobulin was demonstrated in some parts of the primary tumor. Actin and desmin were negative (Table 2). The cytokeratin content, measured by flow cytometry, is shown in Fig. 9A. Mainly the aneuploid cells were cytokeratin-positive.

\section{ONCO-DG 1 cell line}

The ONCO-DG 1 cell line grew in monolayer culture on plastic culture flasks. During the first four passages the monolayers were composed of a mixture of cuboidal epithelial cells and spindle shaped fibroblasts forming nests in confluent cultures. After the fifth passage only the cuboidal epithelial cells remained. Figure 2 shows the 34th subculture. The morphological features were consistent throughout all the experimental procedures.

Table 2. Results

\begin{tabular}{llllll}
\hline Clone & Antigens & $\begin{array}{l}\text { Mono- } \\
\text { layer }\end{array}$ & MCTS & PT & $\begin{array}{l}\text { Xeno- } \\
\text { graft }\end{array}$ \\
\hline KL 1 & Cytokeratin & ++ & ++ & ++ & ++ \\
Vim 3B4 & Vimentin & + & + & ++ & + \\
Dak TgG & Thyreoglobulin & - & - & + & - \\
asm-1 & Actin & - & - & - & n.d. \\
023 & Desmin & - & - & - & n.d. \\
Lot 067 & CEA & + & - & + & + \\
\hline
\end{tabular}

Semiquatitative evaluation of indirect immunoperoxidase staining $-=$ negative,$+=$ weakly positive, $++=$ positive, n.d. $=$ not done

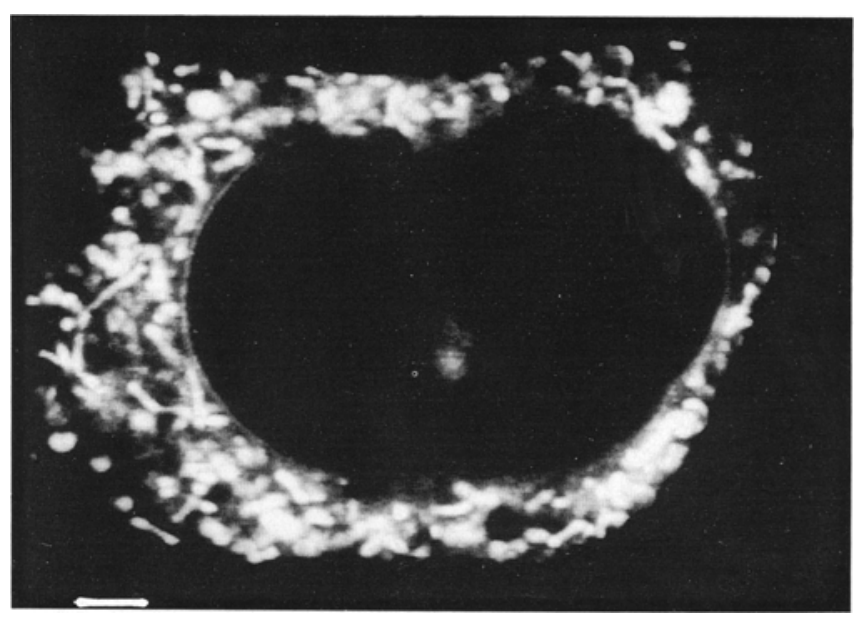

Fig. 4. Rhodamine 123, showing viable staining of mitochondria, 7 day old spheroid, single cell of ONCO-DG $1($ bar $=1 \mu \mathrm{m})$

Table 3. Panel of antibodies used for flow cytometry

\begin{tabular}{llll}
\hline Antibody & Clone & Isotype & Dilution \\
\hline FITC-Conjugated & MNF 116 & \multirow{2}{*}{ m IgG1, k } & $1: 10$ \\
DAKO-CK & & & $1: 30$ \\
& & & $1: 100$ \\
Negative control & DAK-G01 & m IgG1, k & $1: 200$ \\
\hline
\end{tabular}

Company: Dakopatts, Hamburg, FRG

Staining of a homogeneous culture with hematoxylin and eosin showed oxyphilic cells with large basophilic dark nuclei with prominent nucleoli and many regular and pathologic mitotic figures. The cytoplasm was oxyphilic and fine-granulated. Von Kossa silver staining revealed positive deposits like psammoma bodies in the monolayer culture (Fig. 3A) Rhodamine 123 viable staining showed mitochondrial hyperplasia in ONCODG 1 cells (Fig. 4), harvested from MCTS-cells. Monolayer cells showed the same result. Prostate carcinoma (PCA) cells and thyroid adenoma cells, which were stained as controls, possessed only a few mitochondria.

Table 2 shows the immunohistochemical results. The cell line showed a negative staining pattern with the antibody against thyroglobulin. In control experiments the same antibody showed a substantial positive staining with the cultured cells of a microfollicular thyroid adenoma, a follicular and a papillary thyroid carcinoma.

Antibodies against intermediate filaments, such as cytokeratin and vimentin were positive in the monolayer culture. These data obtained by immunohistochemistry of single cells fixed in glass slides were confirmed by flow cytometry (Table 3 ).

Carcinoembryonic antigen was expressed weakly in the cell line.

The DNA-content of the ONCO-DG 1 cells was determined by flow cytometry and chromosome analysis (Figs. 5, 6). A modal number of 61 chromosomes was found. These results are in accordance with the ploidy index of $2.7 \mathrm{c}$ as determined by flow cytometry. 


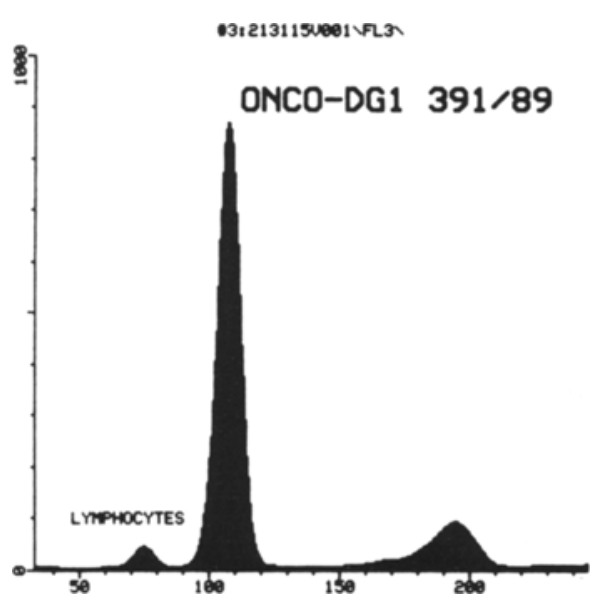

Fig. 5. DNA-flow cytometry of ONCO-DG 1 cell line, Propidium iodide analysis of the DNA-content of ONCO-DG 1 cells in comparison with diploid lymphocytes. $\mathrm{X}$-axis indicates the relative fluorescence intensity

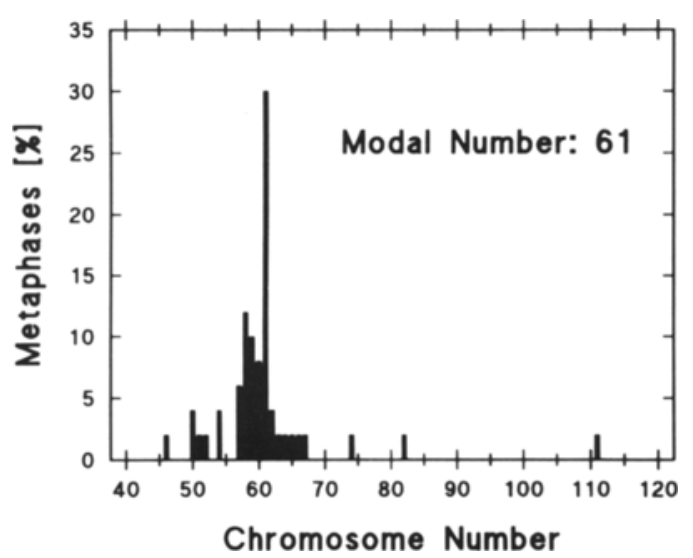

Fig. 6. Chromosome analysis of 50 metaphases examined by image cytometry

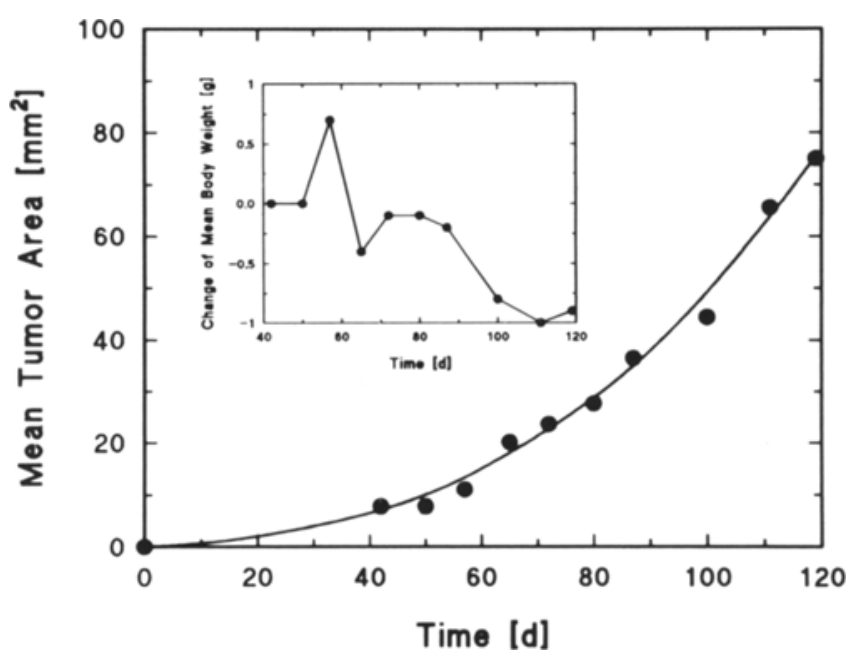

Fig. 7. Growth of nude mouse tumors. Increase in mean tumor area in nude mice within 120 days. Included small picture shows the simultaneous change in body weight of the animals

\section{Tumorigenicity}

Cell suspensions from the 18th in vitro passage of ONCO-DG1 cells were tumorigenic in NMRI nude mice. Between 6 and 8 weeks after s.c. inoculation of the tumor cells, eight of thirteen animals developed palpable tumors in the region of the thoracic mammary fat pad. After 12 weeks, part of a solid tumor was cut into $2 \mathrm{~mm}^{3}$ pieces and transplanted with a trocar into another group of ten 8-week-old male nude mice. After 4 months all the animals developed subcutaneous solid tumors with tumor areas ranging from 20 to $300 \mathrm{~mm}^{2}$ (Fig. 7). The body weights of the animals were only slightly diminished during the course of the experiment (mean body weight \pm SEM (g): d $0=31.4 \pm 2.7$; d119= $30.5 \pm 2.5$ ). Four nude mice revealed axillary lymph node metastases on the side of the palpable tumors.

Two subsequent in vivo passages demonstrated that ONCO-DG1 is serially transplantable into nude mice and can therefore be used as a reproducible in vivo model. Histologically, the nude mouse tumors revealed papillary and follicular structures containing colloid (Fig. 8B), but no psammoma bodies were found. The reculture of nude mouse tumor cells was successful. Both the initial and the recultured nude mouse tumor cells showed negative staining for thyroglobulin but staining for vimentin and cytokeratin was positive. The ploidy index $-2.7 \mathrm{c}$ - was in accordance with the ONCO-DG 1 cells.

\section{Formation of MCTS}

The ONCO-DG 1 and nude mouse tumor cells were able to form MCTS in both the liquid overlay and spinnerflask methods. After 3 days of culturing, tight regular aggregates of category III (Carlsson 1983) were observed. After 7 days von Kossa-positive, concentrically laminated deposits resembling psammoma bodies were formed within the MCTS (Fig. 3B). Rhodamine 123 staining revealed mitochondrial hyperplasia (Fig. 4) and staining for cytokeratin was positive, but that for vimentin, actin, desmin and thyroglobulin, was negative.

\section{Discussion}

The present study is the first to demonstrate the characteristic of papillary thyroid carcinoma cells with oxyphilic differentiation grown in vitro as a monolayer. The cell line formed MCTS and could be transplanted to grow in vivo in nude mice. The formation of papillary and colloid-containing follicular structures in xenografted tumor, the presence of psammoma bodies in the monolayer, and especially the formation of MCTS (in culture, support the thyroid origin of the tumor cells.

The immunoperoxidase studies for cytokeratin and vimentin indicate the presence of these intermediate filaments in the tumor cells. Cytokeratin is very often positive in papillary thyroid carcinomas whereas according to Permanetter et al. (1982), follicular thyroid carcino- 


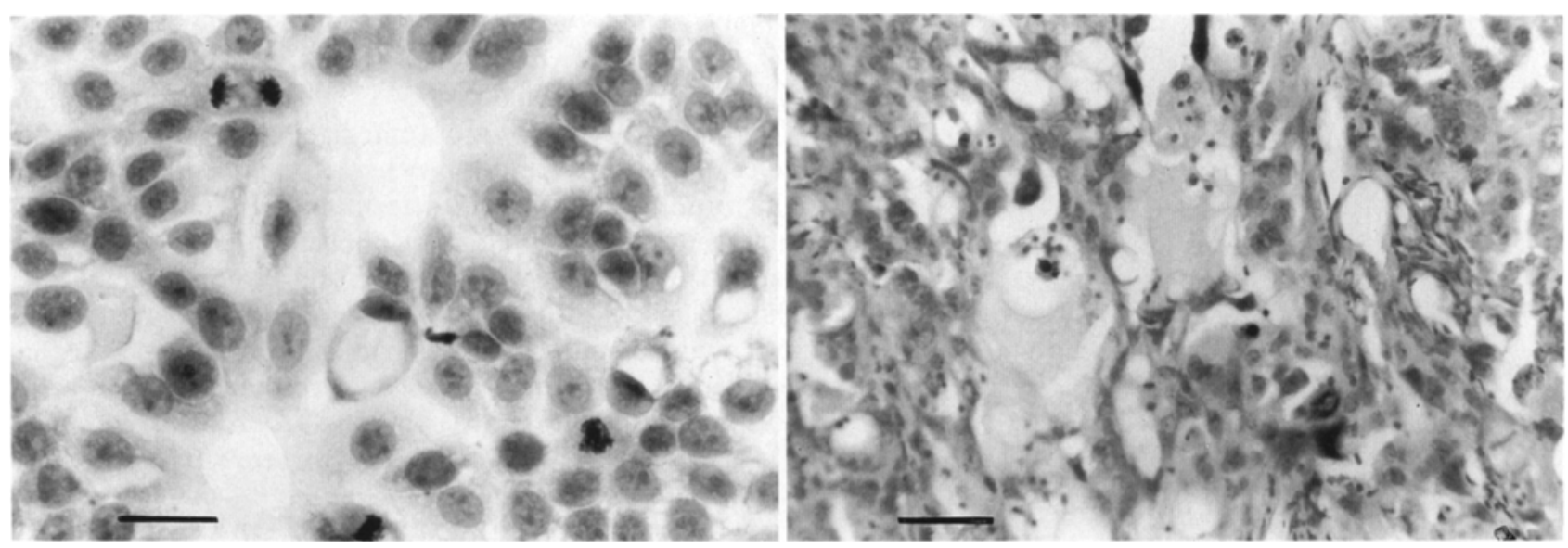

Fig. 8 A. Cultured nude mouse tumor cells. Hematoxylin-eosin staining $(b a r=10 \mu \mathrm{m})$. B Paraffin section of a nude mouse tumor showing colloid-containing follicles. Hematoxylin-eosin staining $($ bar $=14 \mu \mathrm{m})$
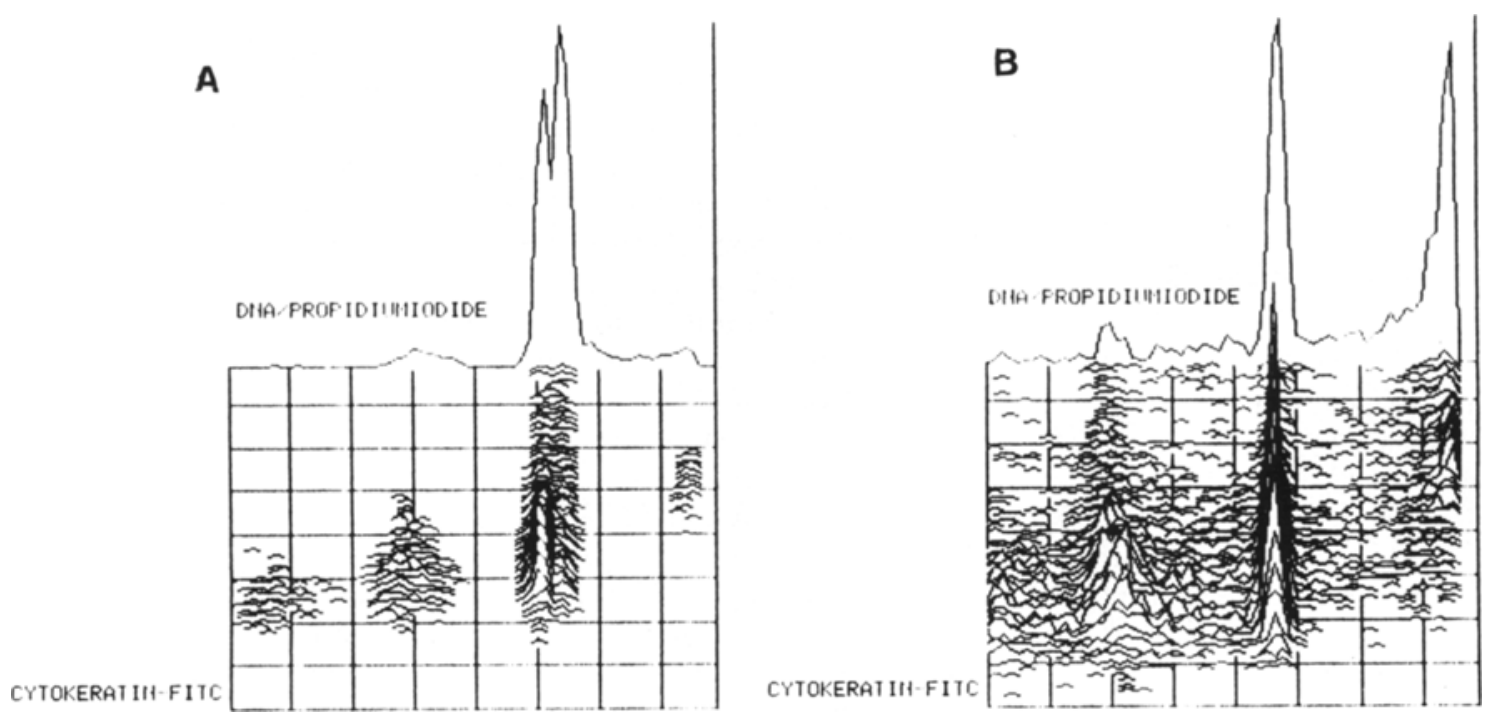

Fig. 9A, B. Dual-parameter flow cytometric analysis of the primary tumor and the ONCO-DG 1 cells. FITC fluorescence on the Y-axis indicates the cytokeratin content and propidium iodide on the X-axis shows the DNA-content. A ONCO-PT-391/89; B ONCO-DG $1-391 / 89$

mas and adenomas show a weak or negative staining for cytokeratin. However, Miettinen et al. (1984) and Schröder et al. (1986) consider cytokeratin to be a reliable marker for thyroid follicular, as well as papillary and medullary carcinomas. Vimentin, an intermediate filament protein normally appearing in cells and tissues mesenchymal origin, can also be demonstrated in some epithelial cells and some tumor cell tissue in culture (Schröder 1988). The coexpression of cytokeratins and vimentin in thyroid epithelial cells of the thyroid gland has been documented by several authors (Viale 1989). Indirect immunoperoxidase staining with a highly specific antibody against thyroglobulin was negative in ONCO-DG 1 cells. Papillary thyroid carcinomas, especially those of the oxyphilic cell type, often contain little or no thyroglobulin, as in the primary tumor used in this study. Böcker (1975) showed a positive correlation between immunohistochemically of demonstrated thyroglobulin content and the degree of differentiation in follicular thyroid adenomas. Permanetter et al. (1982) report that papillary thyroid carcinomas display only a weak reaction against antithyroglobulin serum whereas follicular thyroid tumors react strongly. Carcinoembryonic antigen (CEA) was weakly detected in the primary tumor and the ONCO-DG 1 cells. The weak fluorescence for anti-CEA indicates either that the cells have weak CEA-expression or that a cross reaction with NCA (Nonspecific Cross-reacting Antigen) is occurring. We used a polyclonal commercially available CEA-antibody (Table 1) and it is well documented that most polyclonal CEA-antisera will cross-react with NCA which is expressed in many normal and neoplastic tissues (Schröder 1988). The results of the indirect immunofluorescence staining by flow cytometry supported the data obtained by immunohistology.

Concerning the DNA content, the tumor shows an aneuploid DNA-histogramm (2.7c). Rainwater et al. (1986) reported that $51 \%$ of oxyphilic thyroid carcino- 
mas had a DNA aneuploid peak. This study was processed by flow cytometry on extracted nuclei from deparaffinized tissue blocks.

Mitochondrial hyperplasia was shown using the laser dye rhodamine 123 by confocal laser scanning microscopy. The controls (follicular thyroid adenoma and papillary thyroid carcinoma cells) only contained a few mitochondria. Several authors have shown the presence of mitochondria with rhodamine in living human cells (Goldstein et al. 1981; Johnson et al. 1980). Recently it was reported that oxyphilic thyroid carcinomas with an abundance of mitochondria reveal an increase in enzymatic activities of respiratory complexes I, II, III, IV and V. Furthermore a parallel increase in the mitochondrial DNA content could be found (Ebner et al. 1991). The finding that rhodamine 123 revealed an abundance of mitochondria in ONCO-DG 1 cells suggests that it would be interesting to examine the enzymatic activities of respiratory complexes and the mitochondrial DNA content in our cell line. Ishizaka and coworkers (1990) have obtained ret cDNAs from a human papillary thyroid carcinoma cell line, TPC-1.

The von Kossa silver staining gives a positive result in psammoma body-like structures. As control experiments we used different cultured papillary thyroid carcinoma cells in two- and three-dimensional systems. All these experiments were negative for psammoma body formation. Psammoma bodies are a frequent finding in papillary thyroid carcinomas (Hedinger et al. 1988). These coarse or delicate, concentrically laminated bodies stain dark blue with hematoxylin and are composed of calcium and sometimes of iron salts bound by an acid mucopolysaccharide. Psammoma bodies must be differentiated from stromal dystrophic calcifications or colloid calcifications, which are common in many thyroid lesions. True psammoma bodies are formed by focal infarction of the tips of papillae, probably the result of ischemic necrosis. This mode of calcification is typical for cell necrosis as a result of secretion blockage. Presumably the delicate vessels undergo thrombosis or damage as the result of microtrauma. Progressive infarction of the papilla and ensuing calcium deposition leads to lamellation (Johannessen et al. 1980). Our demonstration of the occurrence of psammoma bodies in cultured cells indicate that other factors may be involved. The fact that psammoma-like bodies formed in MCTS, which are avascular aggregates of tumor cells, indicates that non-vascular mechanisms, related to the cellular environment, tumor micromilieu and metabolism, oxygen concentration and $\mathrm{pH}$ may be important. Clearly, further experiments are required. Degenerative colloid calcifications are laminated, basophilic but intrafollicular structures. They are often present in follicular tumors of the thyroid gland, particularly in oxyphilic tumors (Hedinger et al. 1988). These von Kossa-positive deposits are very similar to psammoma bodies. The primary papillary carcinoma from which the ONCO-DG1 cell line was derived, showed papillary structures and occasional follicular colloid-containing structures, but no colloid calcification. With the methods used in our experiments we cannot definitely state whether or not these structures are really psammoma bodies. Electronmicroscopic and energy dispersive $\mathrm{x}$-ray analyses will be made in our next experiments.

Injection of cells of the tumor cell line ONCO-DG 1 produced subcutaneous tumors in nude mouse. Examination of these showed solid tumors with papillary and follicular structures containing colloid. Furthermore axillary lymph node metastases occurred indicating that this cell line may be a useful model for in vivo studies.

The cell line is able to form spheroids by the liquid overlay and spinnerflask techniques several other cell lanes capable of forming multicellular tumor spheroids in culture have been reported. Carlsson (1983) tested several types of human cells growing normally in monolayer or suspension culture to examine their ability of forming MCTS and to grow in MCTS form. Westermark (Carlsson, 1983) has established h TH7 tumor cells of a human anaplastic thyroid carcinoma of the giant size type. h TH7 cells form MCTS with smooth surfaces in 1-3 days. Mulcahy (1985) reported the growth and morphology of FRTL-5 rat thyroid epithelial cells which grew as MCTS in spinnerflask culture. Pfragner and associates (1990) established a human medullary carcinoma cell line which grew in a suspension of single cells and spherical cell aggregates.

Our interest is the coculture of human thyroid papillary carcinoma cells with human endothelial cell layers. This is a reliable model for structuring cell-cell interactions (Knünchel et al. 1988). In this experimental system we use MCTS of follicular thyroid carcinomas and benign follicular adenomas as controls. The question arises whether or not there is a difference in tumor cell-endothelial cell interaction between papillary and follicular thyroid carcinomas. This could be a possible experimental approach to determine why papillary thyroid carcinomas preferentially show lymphatic spread and follicular carcinomas show mainly vascular dissemination.

The intercellular adhesion molecule-1 (ICAM-1) is expressed on the surface of cultured umbilical vein endothelial cells (Dustin et al. 1988) and is a ligand for the Lymphocyte-Function-Associated Antigen 1 (Marlin et al. 1987). We intend to examine the coculture complex with regard to the expression of cell adhesion molecules and the use of activation and proliferation markers of endothelial cells.

Acknowledgements. The authors thank Miss Sigrid Meckl and Miss Gabriele Pennartz for technical assistance. This work was support by the Deutsche Forschungsgemeinschaft, DFG.

\section{References}

Böcker W (1975) Elektronenmikroskopische und immunhistochemische Untersuchungen an Schilddrüsentumoren. Verh Dtsch Ges Pathol 59:554

Carlsson J, Nilsson K, Ponten J, Sundström C, Larsson E, Bergh J, Pahlman S, Busch C, Collins VP (1983) Formation and growth of multicellular spheroids of human origin. Int J Cancer $31: 535-533$

Dustin ML, Springer TA (1988) Lymphocyte function-associated antigen-1 (LFA-1) Interaction with intercellular adhesion molecule-1 (ICAM-1) is one of at least three mechanisms for lym- 
phocyte adhesion to cultured endothelial cells. J Cell Biol 107:321-331

Ebner D, Rödel G, Pavenstaedt I, Haferkamp O (1991) Functional and molecular analysis of mitochondria in thyroid oncocytoma. Virchows Arch [B] 60:139-144

Estour B, Van Herle AJ, Juillard GJF, Totanes TL, Sparkes RJ, Giuliano AE, Klandorf H (1989) Characterization of a human follicular thyroid carcinoma cell line (UCLA RO 82 W1). Virchows Arch [B] 57:167-174

Goldstein S, Korczack LB (1981) Status of mitochondria in living human fibroblasts during growth and senescence in vitro: Use of the laser dye rhodamine 123. J Cell Biol 91:392-397

Hedinger C, Williams ED, Sobin LH (1988) World Health Organization, International Histological Classification of Tumours: Histological typing of thyroid tumours. Springer, New York, 2nd edition

Ishizaka Y, Ushijima T, Sugimura T, Nagao M (1990) cDNA cloning and characterization of ret activated in a human papillary thyroid carcinoma cell line. Biochem Biophys Res Commun $168: 402-408$

Johannessen JV, Sobrinho-Simoes M (1980) The origin and significance of thyroid psammoma bodies. Lab Invest 43:287-296

Johnson LV, Walsh ML, Bo Chen L (1980) Localization of mitochondria in living cells with rhodamine 123. Proc Natl Acad Sci USA 77:990-994

Knüchel R, Feichtinger J, Recktenwald A, Hollweg HG, Franke P, Jakse G, Rammal E, Hofstädter F (1988) Interactions between bladder tumor cells as tumor spheroids from the cell line $J 82$ and human endothelial cells in vitro. J Urol 139:640645

Marlin SD, Springer TA (1987) Purified intercellular adhesion molecule-1 (ICAM-1) is a ligand for lymphocyte function-associated antigen 1 (LFA-1). Cell 51:813-819

Miettinen M, Franssila KO, Lehto VP, Paasivuo R, Virtanen I (1984) Expression of intermediate filament proteins in thyroid gland and thyroid tumors. Lab Invest 50:262-270

Miyamoto M, Sugawa H, Mori T, Hase K, Kuma K, Imura H (1988) Epidermal growth factor receptors on cultured neoplastic human thyroid cells and effects of epidermal growth factor and thyroid stimulating hormone on their growth. Cancer Res $48: 3652-3656$
Mulcahy RT, Rosenkrans W Jr, Penney DP, Cooper RA (1985) The growth and morphology of FRTL-5 thyroid epithelial cells grown as multicellular spheroids in vitro. Vitro Cell, Dev Biol $21: 513-520$

Permanetter W, Nathrath WBJ, Löhrs U (1982) Immunohistochemical analysis of thyroglobulin and keratin in benign and malignant thyroid tumours. Virchows Arch [A] 398:221-228

Pfragner R, Höfler H, Behmel A, Ingolic E, Walser V (1990) Establishment and characterization of a continuous cell line MTCSK derived from a human medullary thyroid carcinoma. Cancer Res 50:4160-4166

Polak JM, Van Noorden S (1986) Immunocytochemistry. Modern methods and applications. II. Edition, Wright, Bristol, England

Rainwater LM, Farrow GM, Hay ID, Lieber MM (1986) Oncocytotic tumours of the salivary gland, kidney and thyroid: nuclear DNA patterns studied by flow cytometry. Br J Cancer 53: 799 804

Schröder S, Dockhorn-Dworniczak B, Kastendieck H, Böcker W, Franke WW (1986) Intermediate-filament expression in thyroid gland carcinomas. Virchows Arch [A] 409:751-766

Schröder S (1988) Pathologie und Klinik maligner Schilddrüsentumoren. Klassifikation, Immunhistologie, Prognosekriterien. Gustav Fischer, Stuttgart New York

Shea RC, Sherwood ME, Flotte TJ, Scholz M, Hasan T (1990) Rhodamine 123 phototoxicity in laser-irradiated MGH-U1 human carcinoma cells studied in vitro by electron and confocal laser scanning microscopy. Cancer Res 50:4167-4172

UICC (1989) TNM Klassifizierung der malignen Tumoren und allgemeine Regeln zur Anwendung des TNM-Systems. Springer, Berlin Heidelberg New York, 3d edition

Viale G, Dell'Orto P, Coggi G, Gambacorta M (1989) Coexpression of cytokeratins and vimentin in normal and diseased thyroid glands. Lack of diagnostic utility of vimentin immunostaining. AM J Surg Pathol 13:1034-1040

Volm M, Drings P, Mattern J, Sonka J, Vogt-Moykopf I, Wayss K (1985) Prognostic significance of DNA patterns and resistance-predictive tests in non-small cell lung carcinoma. Cancer $56: 1396-1403$ 